\title{
CORRELATION BETWEEN GLYCOSYLATED HAEMOGLOBIN, LIPID PROFILE AND THYROID FUNCTION AMONG PATIENTS WITH TYPE 2 DIABETES MELLITUS
}

\author{
Ksh. Achouba Singh'1, R. K. Banashree Devi², M. D. Sadam Hussain ${ }^{3}$
}

${ }^{1}$ Associate Professor, Department of Endocrinology, Jawaharlal Nehru Institute of Medical Sciences (JNIMS), Imphal, Manipur, India. ${ }_{2}^{2}$ Associate Professor, Department of Pathology, Jawaharlal Nehru Institute of Medical Sciences (JNIMS), Imphal, Manipur, India. ${ }^{3}$ Postgraduate Trainee, Department of Medicine, Jawaharlal Nehru Institute of Medical Sciences (JNIMS), Imphal, Manipur, India.

\section{ABSTRACT}

\section{BACKGROUND}

The prevalence of Diabetes is increasing at an alarming rate all over the world. Among the non-communicable diseases, diabetes is second highest burden, second only to cardiovascular disease in India. Type 2 diabetes is commonly associated with obesity, hypertension \& cardiovascular diseases. Dyslipidaemia is one of the major factors for cardiovascular diseases. In diabetes mellitus, Total Cholesterol, Triglycerides, Low Density Lipoprotein are elevated \& High-Density Lipoprotein is decreased. HbA1c is widely used as a measure of mean Glycaemia; it is a measure of risk factor for development of diabetic complications. Thyroid dysfunction is one of the commonest endocrine dysfunctions that is rampant in most of the populations around the world, especially the diabetics.

Aims \& Objectives-

1. To determine the levels of TSH and glycosylated haemoglobin (HbA1c) among Type 2 DM patients.

2. To correlate between TSH and HbA1c and different types of lipids and HbA1c among type 2 DM patients.

\section{MATERIALS AND METHODS}

A cross sectional study was conducted at Department of Endocrinology, JNIMS, during the period from August 2017 to December 2017, including 124 male and female patients diagnosed with diabetes mellitus (DM) type 2 and excluding patients already on antithyroid and lipid lowering agents and those who do not give consent for the study. They were subjected to detailed history followed by clinical examination, laboratory workup including glycaemic status, lipid profile and TSH, after getting informed consent.

\section{RESULTS}

The result showed increased mean levels of HbA1c (8.2\%) and normal level of thyroid stimulating hormone (TSH) (5.6 mlU/L). The results also showed a weak positive correlation between HbA1c and TSH $(r=0.212, \mathrm{P}=0.034)$. HbA1c showed Direct \& significant correlation with Total Cholesterol and LDL.

\section{CONCLUSION}

These findings suggest that HbA1c can be used as a good parameter for predicting the Lipid Profile thereby useful in prevention of any future cardiovascular events. The increased blood glucose could trigger anterior pituitary gland to increase secre tion of TSH.

\section{KEY WORDS}

Type 2 DM, HbA1c, Lipid Profile, TSH.

HOW TO CITE THIS ARTICLE: Singh KA, Devi RKB, Hussain MDS. Correlation between glycosylated haemoglobin, lipid profile and thyroid function among patients with type 2 diabetes mellitus. J. Evolution Med. Dent. Sci. 2018;7(46):4947-4949, DOI: $10.14260 /$ jemds/2018/1101

\section{BACKGROUND}

Diabetes mellitus (DM) is a group of metabolic diseases characterized by hyperglycaemia resulting from defects in insulin secretion, insulin action, or both.[1] Recent estimates indicate that there were 171 million people in the world with diabetes in the year 2000 and this is projected to increase to 366 million by 2030.[2] The risk of chronic complications in patients of DM depends on the duration of hyperglycaemia, and they usually become manifest in the second decade of the development of DM. ${ }^{[3,4]}$

'Financial or Other Competing Interest': None.

Submission 16-10-2018, Peer Review 31-10-2018,

Acceptance 02-11-2018, Published 12-11-2018.

Corresponding Author:

R. K. Banashree Devi,

Uripok Bachaspati Maning Leikai,

Imphal-795001, Manipur, India.

E-mail: rkbanashree@gmail.com

DOI: $10.14260 /$ jemds $/ 2018 / 1101$
Thyroid dysfunction is one of the commonest endocrine dysfunctions that is rampant in most of the populations around the world, especially in diabetics.

The frequency of thyroid dysfunction is higher, both in the aged and the females.[5-7]

Hypothyroidism is the most predominant type of thyroid disease; the features of the disease are similar in both the diabetics and nondiabetics. It can lower the glucose level in blood, in addition, to increasing insulin resistance. ${ }^{[8]}$ In some conditions, diabetes is also related to abnormal thyroid function, involving very low glucose level in the blood and also renal disorders. $[9,10]$ The presence of diabetes is also related to the insufficiency of the replacement of thyroid hormone in elderly patients with hypothyroidism.[11]

Since, adequate glycemic control can delay development of diabetic complication, the purpose of this study was to measure $\mathrm{HbA1c}$ in diabetic patients and bring out a possible correlation between thyroid hormones, HbA1c and different types of lipids, in order to highlight the significance of such a 
correlation which can prevent exacerbation of cardiovascular risk-related mortality.

\section{Aim of the Study}

1. To determine the levels of TSH and glycosylated haemoglobin (HbA1c) among Type 2 DM patients.

2. To correlate between TSH and HbA1c and different types of lipids and HbA1c among type 2 DM patients.

\section{MATERIALS AND METHODS}

\section{Subjects}

The present study was conducted on 124 patients with Type 2 diabetes mellitus attending Diabetic Clinic in JNIMS Endocrinology Department from August 2017 to December 2017. The data collected from each patient included Age, Sex, Duration of Disease, Body Mass Index (BMI), Fasting \& Post Prandial Glucose Level, HbA1c, TSH, Total Cholesterol, Triglycerides, HDL, LDL and VLDL.

\section{Study Design}

This is a cross sectional study.

\section{Inclusion Criteria}

Male and female patients diagnosed with DM type 2, of all age group.

\section{Exclusion Criteria}

Patients already on antithyroid and lipid lowering agents.

\section{Blood Collection}

$5 \mathrm{ml}$ of blood was drawn from all the above subjects from the anterior cubital vein using sterile disposable syringe. While $1 \mathrm{ml}$ blood was collected for blood sugar estimation, $4 \mathrm{ml}$ of serum for for lipid profile testing, TSH. Estimation of plasma Glucose was by Glucose Oxidase Peroxidase method, Total Cholesterol by CHOD-PAP, Triglycerides by GPO-PAP, HDL by Homogenous Enzymatic Colorimetric test, VLDL Cholesterol \& LDL Cholesterol were calculated using the Friedewald Equation, \& HbA1c by immunochromatographic method TSH by chemiluminescence/ELISA.

\section{Statistical Analysis}

The statistical analyses were performed using SPSS version 20. The descriptive results were expressed as mean \pm standard deviation and percentage. An independent t-test was used to compare mean values of each parameter among the groups. To observe possible relationships between parameters, Pearson's correlation coefficient ( $\mathrm{r}$ ) was used. All variables with $\mathrm{p}$ - value less than 0.05 were considered as statistical significance.

\section{RESULTS}

Of the 124 patients 60 patients were female and 64 were male. According to NCEPATPIII guideline, Hypercholesterolemia is defined as TC $>200 \mathrm{mg} / \mathrm{dl}$, High LDL when value is $>100 \mathrm{mg} / \mathrm{dl}$, Hypertriglyceridemia as TAG $>150$ $\mathrm{mg} / \mathrm{dl}$, \& low HDL when value $<40 \mathrm{mg} / \mathrm{dl}$. Dyslipidaemia was defined by presence of one or more than one abnormal serum lipid concentration. Diabetes was defined as per American Diabetic Association (ADA) criteria. The mean Total Cholesterol $175.17 \mathrm{mg} / \mathrm{dl}$, TGL 168.50, HDL $45.88 \mathrm{mg} / \mathrm{dl}$, VLDL $33.21 \mathrm{mg} / \mathrm{dl}$, LDL $94.75 \mathrm{mg} / \mathrm{dl}$ was seen in patients having HbA1c of less than 6.6 \& the mean Total Cholesterol
$190.17 \mathrm{mg} / \mathrm{dl}$, TG $189.16 \mathrm{mg} / \mathrm{dl}$, HDL $43.81 \mathrm{mg} / \mathrm{dl}$, VLDL $39.88 \mathrm{mg} / \mathrm{dl}$, LDL $109.52 \mathrm{mg} / \mathrm{dl}$ was seen in patients having HbA1c of more than 6.6. By comparing both the groups it is found that though the lipid parameters were elevated in patients having glycemic status $(\mathrm{HbA} 1 \mathrm{c}>6.6)$, all these parameters were positively \& significantly elevated for Total Cholesterol and LDL only. The mean concentration values of patients for thyroid stimulating hormone (TSH) and HbA1c were $5.6 \mathrm{mIU} / \mathrm{L}$ and $8.2 \%$. TSH value less than 0.40 or more than 6.40 was taken as abnormal

A significantly positive correlation was found between HbA1c and TSH $(r=0.212 \mathrm{P}=0.034)$ [Figure 1]. The correlation results between $\mathrm{HbA1c}$ and LDL were significantly positive $(\mathrm{r}=2.97, \mathrm{P}=0.003)$ [Figure 3]. A positively significantly correlation was found between $\mathrm{HbA1c}$ and cholesterol $(\mathrm{r}=0.258, \mathrm{P}=0.001)$ [Figure 2].

\begin{tabular}{|c|c|c|}
\hline Variable & Number & Percentage \\
\hline Male & 64 & 51 \\
\hline Female & 60 & 49 \\
\hline Table 1. Distribution of Patients According to Gender
\end{tabular}

Table 1. Distribution of Patients According to Gender

\begin{tabular}{|c|c|}
\hline Variable & Mean $\mathbf{\text { SD }}$ \\
\hline HbA1c & $8.2 \pm 1.8$ \\
\hline TSH & $5.6 \pm 3.25$ \\
\hline Total Cholesterol & $182.6 \pm 35.5$ \\
\hline LDL & $102 \pm 31$ \\
\hline Triglyceride & $178.8 \pm 65.2$ \\
\hline HDL & $44.9 \pm 12.3$ \\
\hline VLDL & $36.5 \pm 17.5$ \\
\hline Table 2. Means and SD of Different Variables \\
\hline
\end{tabular}

\begin{tabular}{|c|c|c|c|c|c|}
\hline Lipid Profile & HbA1c & $\mathbf{N}$ & Mean & SD & $\begin{array}{c}P \text { - } \\
\text { value }\end{array}$ \\
\hline \multirow{2}{*}{ Total Cholesterol } & $<6.6$ & 24 & 175.17 & 33.80 & \multirow{2}{*}{0.067} \\
\hline & $>6.6$ & 100 & 190.17 & 36.33 & \\
\hline \multirow[b]{2}{*}{ Triglyceride } & $<6.6$ & 24 & 168.40 & 70.37 & \multirow{2}{*}{0.287} \\
\hline & $>6.6$ & 100 & 189.16 & 88.43 & \\
\hline \multirow[b]{2}{*}{ HDL } & $<6.6$ & 24 & 45.88 & 13.58 & \multirow{2}{*}{0.481} \\
\hline & $>6.6$ & 100 & 43.81 & 12.74 & \\
\hline \multirow[b]{2}{*}{ LDL } & $<6.6$ & 24 & 94.75 & 29.84 & \multirow{2}{*}{0.040} \\
\hline & $>6.6$ & 100 & 109.52 & 31.81 & \\
\hline \multirow[b]{2}{*}{ VLDL } & $<6.6$ & 24 & 33.21 & 14.13 & \multirow{2}{*}{0.092} \\
\hline & $>6.6$ & 100 & 39.88 & 17.98 & \\
\hline
\end{tabular}

Table 3. Comparison of Lipid Profile According to the Glycaemic Status

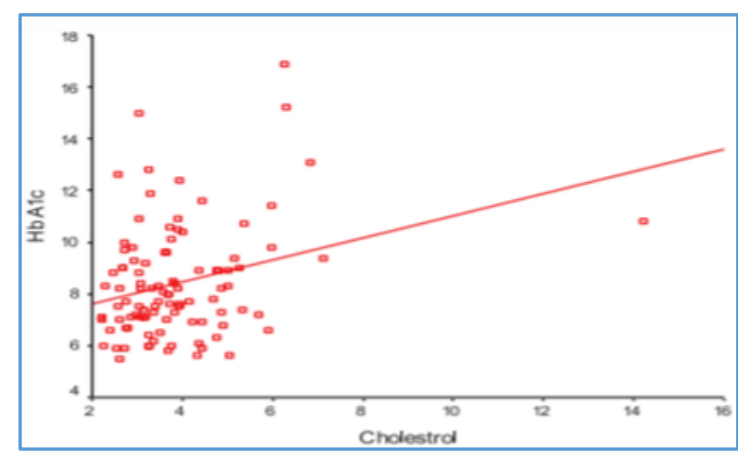

Figure 1. A Scatter Plot shows the Relationship between Levels of Thyroid Stimulating Hormone in pmol/L and Glycosylated Haemoglobin in \% ( $r=0.212$ and $P>0.05)$ 


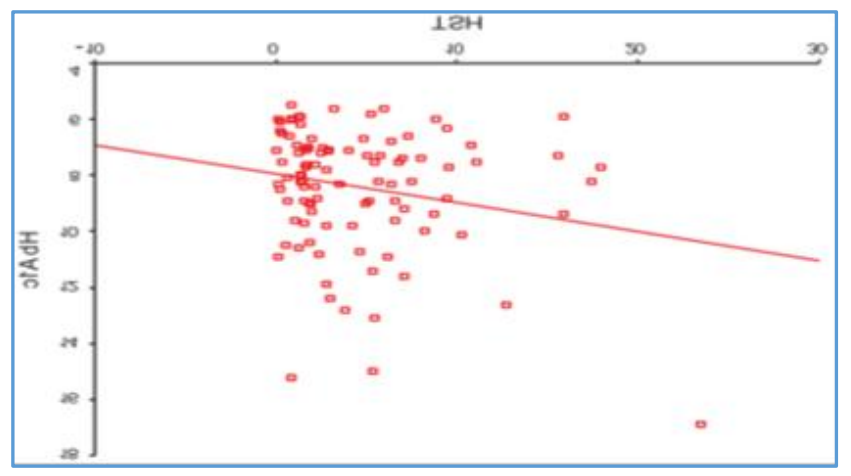

Figure 2. A Scatter Plot shows the Relationship between Levels of Cholesterol in $\mathrm{mmol} / \mathrm{L}$ and Glycosylated Haemoglobin in \% ( $r=0.258$ and $P>0.05)$

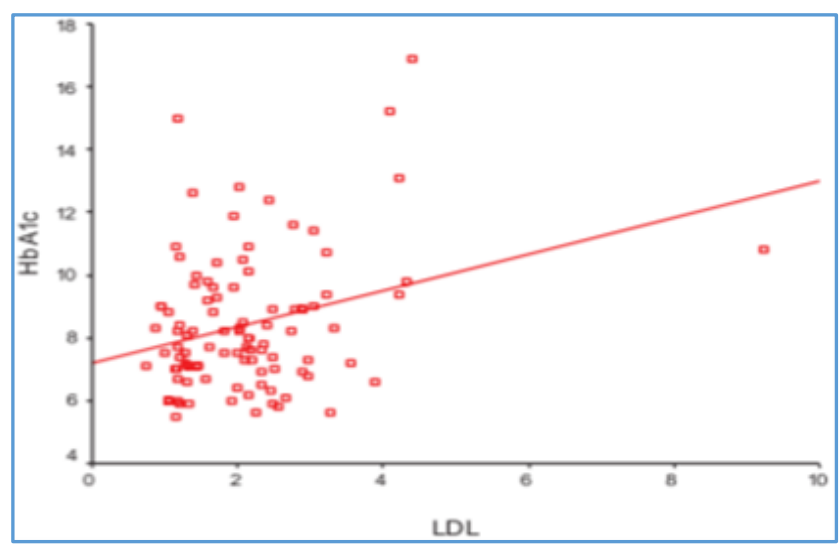

Figure 3. A Scatter Plot shows the Relationship between Levels of Low-Density Lipoprotein in $\mathrm{mmol} / \mathrm{L}$ and Glycosylated Haemoglobin in \% $(r=0.297$ and $P>0.01)$

\section{DISCUSSION}

Since the measurement of HbA1c levels is important not only for monitoring of diabetes, the results of our study showed an obvious elevation of $\mathrm{HbA} 1 \mathrm{c}$ levels in patients diagnosed with DM are in corroboration with the results of Vikhe et al., and Saha et al.[10,11] Consequently impaired lipid metabolism resulting from uncontrolled hyperglycaemia has been implicated in cardiovascular complications in diabetes patients, this fact support our result which showed a relation between HbA1c, total cholesterol and LDL in patients with DM, which are also confirmed by Khan et al.,[12] who stated that $\mathrm{HbA1c}$ exhibited direct correlations with cholesterol and LDL

Our observation on the lack of variation in TSH level is not in harmony with the results of Cappelli et al.,[13] these differences appear to be also due to DM medications. Furthermore, the result of correlation test showed a positive correlation between $\mathrm{HbA} 1 \mathrm{c}$ and TSH in type $2 \mathrm{DM}$, these observations are consistent with previous studies Udiong et $\mathrm{al}^{,[14]}$ who reported significant association between $\mathrm{HbA1c}$ and TSH. So, it is recommended that blood glucose for the diabetic patient should be maintained within the reference value in order to avoid the complications. Furthermore, regular check for lipid profile and thyroid function test should be requested every 3 months for all diabetic patients as recommended by many diabetic associations.

\section{CONCLUSION}

These findings suggest that HbA1c which guides in the management of diabetes can also be used as a good parameter for predicting the lipid levels. This study also highlights that increased blood glucose level could trigger anterior pituitary to increase secretion of TSH, hence clinical interpretation of raised TSH in the face of high blood sugar level should be cautious. Further studies with larger cohort of diabetes patients is required.

\section{ACKNOWLEDGEMENT}

We are thankful to the Department of Haematology (Pathology) and their staff for their kind co-operation.

\section{REFERENCES}

[1] American Diabetes Association. Diagnosis and classification of diabetes mellitus. Diabetes Care 2012;35 (Suppl 1):S64-71.

[2] Wild S, Roglic G, Green A, et al. Global prevalence of diabetes: estimates for the year 2000 and projections for 2030. Diabetes Care 2004;27(5):1047-53.

[3] Joshi SR, Parikh RM. India - Diabetes capital of the world: now heading towards hypertension. J Assoc Physicians India 2007;55:323-4.

[4] Alzaid AA. Time to declare war on diabetes. Ann Saudi Med 1997;17(2):154-5.

[5] Canaris GJ, Manowitz NR, Mayor G, et al. The Colorado thyroid disease prevalence study. Arch Intern Med 2000;160(4):526-34.

[6] Hollowell JG, Staehling NW, Flanders WD, et al. Serum TSH, T(4) and thyroid antibodies in the United States population (1988 to 1994): National Health and Nutrition Examination Survey (NHANES III). J Clin Endocrinol Metab 2002;87(2):489-99.

[7] Celani MF, Bonati ME, Stucci N. Prevalence of abnormal thyrotropin concentrations measured by a sensitive assay in patients with type 2 diabetes mellitus. Diabetes Res 1994;27(1):15-25.

[8] Rai S, Kumar JA, Prajna K, et al. Thyroid function in type 2 diabetes mellitus and in diabetic nephropathy. J Clin Diagn Res 2013;7(8):1583-5.

[9] Somwaru LL, Arnold AM, Joshi N, et al. High frequency of and factors associated with thyroid hormone overreplacement and under-replacement in men and women aged 65 and over. J Clin Endocrinol Metab 2009;94(4):1342-5.

[10] Vikhe VB, Kanitkar SA, Tamakuwala KK, et al. Thyroid dysfunction in patient with type 2 diabetes mellitus at tertiary care centre. Natl J Med Res 2013;3(4):377-80.

[11] Saha HR, Sarkar BC, Khan SA, et al. A comparative study of thyroid hormone and lipid status in diabetic and non-diabetic adults. Open Access Sci Rep 2012;1:1-5.

[12] Khan HA, Sobki SH, Khan SA. Association between glycaemic control and serum lipids profile in type 2 diabetic patients: HbA1c predicts dyslipidaemia. Clin Exp Med 2007;7(1):24-9.

[13] Cappelli C, Rotondi M, Pirola I, et al. TSH-lowering effect of metformin in type 2 diabetic patients: differences between euthyroid, untreated hypothyroid, and euthyroid on L-T4 therapy patients. Diabetes Care 2009;32(9):1589-90.

[14] Udiong CE, Etukudoh MH, Essien OE. Thyroid hormones and glycemic indices in types 1 and 2 diabetes mellitus. J Med Lab Sci 2007;16(2):1192-5. 